\title{
Recovery ability of human adipose stem cells exposed to cobalt nanoparticles: outcome of dissolution
}

\author{
Marina Borgese ${ }^{1}$, Federica Rossi ${ }^{1}$, Patrizia Bonfanti ${ }^{2}$, Anita Colombo², Paride Mantecca ${ }^{2}$, \\ Luigi Valdatta1, Giovanni Bernardini ${ }^{1}$ \& Rosalba Gornati*,1 (iD \\ ${ }^{1}$ Dipartimento di Biotecnologie e Scienze della Vita, Università degli Studi dell'Insubria, V. J. H. Dunant 3, 21100, Varese, Italy \\ ${ }^{2}$ Dipartimento di Scienze dell'Ambiente e della Terra, Università degli Studi di Milano Bicocca, P.zza della Scienza 1, 20126, Milano, \\ Italy \\ *Author for correspondence: Tel.: +39 033242 1314; Fax: +39 033242 1500; rosalba.gornati@uninsubria.it
}

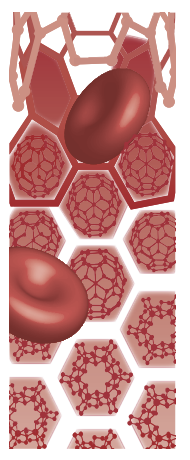

Aim: To demonstrate that cobalt nanoparticles doses are safe for use in humans and to understand the consequences of the particulate effects, which may persist inside the cells. Materials \& methods: Human adipose stem cells were used. We evaluated cell recovery by viability test, morphology and ultrastructure using electronic and optical microscopy, while gene expression was assessed utilizing real-time PCR. Results: After exposure, most stem cells recovered their normal function. $\mathrm{CO}_{3} \mathrm{O}_{4}$-nanoparticles remained inside the cell for the entirety of the considered time. A slight modification of gene expression was observed in the exposed cells. Conclusion: After exposure to $100 \mathrm{M}$ cobalt nanoparticles, most cells returned to normal function. Nanoparticle toxicity was due to ions released by dissolution as well as from the nanoparticles themselves.

First draft submitted: 14 May 2019; Accepted for publication: 29 November 2019; Published online: 7 February 2020

Keywords: cell morphology • inductively coupled plasma mass spectrometry $\bullet$ molecular biomarkers $\bullet$ nanotoxicology • TEM

Cobalt $(\mathrm{Co})$, along with iron $(\mathrm{Fe})$ and nickel $(\mathrm{Ni})$, is a transition metal belonging to group VIIIb of the periodic table. It is an essential element for cell physiology and animal health; in fact, Co is an important constituent of vitamin B12 and is involved in several cell pathways, such as the metabolism of fats and carbohydrates, the conversion of folate into their active form, protein synthesis and the prevention of demyelination [1]. Co deficiency is quite unusual and potentially lethal; conversely, Co intoxication, caused by excessive levels in the body, occurs more frequently and is dangerous as well [2].

Along with $\mathrm{Fe}$ and $\mathrm{Ni}$, Co is one of the three naturally occurring magnetic metals; it is able to retain its magnetic properties at high temperatures. Therefore, Co has many applications, such as for energy storage systems and catalytic processes [3]. In particular, Co, in its bulk form, is used for green technologies and is also an integral component in powering electric vehicles, wind and wave generators, solar energy technologies sensors, electrochemistry and magnetic fluids $[4,5]$. However, at the nanoscale dimension, too, Co is promising for several nanotechnological applications ranging from chemistry to nanomedicine, where it is used as a highly sensitive MRI contrast agent [6]. In this scenario, an issue that should be considered is the exponential growth of production, use and discharge of Co nanoparticles (Co-NPs). Consequently, the human body is very likely to come into contact, intentionally or not, with Co-NPs that may easily enter the body in different ways [7-9], encounter cells of different tissues and then act on them by perturbing their physiology [10]. In this perspective, special attention should be paid to the presence of multipotent stem cells, a population residing in almost all human tissues that fulfills important functions, including renewal, repair and remodeling [11]. Among the different stem cell populations, mesenchymal stem cells (MSCs) are very interesting due to their great potential in many medical applications, such as regenerative medicine, bone marrow transplantation and orthopedic injuries. Unfortunately, MSCs are more sensitive to NP exposure than are differentiated cells [10,12-14]; thus, it is important to evaluate the effects of the Co-NPs on MSCs and to determine a 
cell's ability to recover after exposure. Furthermore, another aspect that should be taken into account when studying NPs is so-called 'dissolution', a phenomenon that can occur when NPs are placed in an aqueous solvent such as culture medium or saline solution. In previous studies, we demonstrated that Co-NPs can gradually dissolve in the culture medium, generating ions whose presence may contribute to NP toxicity $[3,9,15]$.

The intention of this study was to evaluate the outcome of a single 3-h exposure of zerovalent Co-NPs (zCo-NPs), Co-oxide $\left(\mathrm{Co}_{3} \mathrm{O}_{4}\right.$-NPs) and $\mathrm{Co}$ ions $\left(\mathrm{Co}^{2+}\right)$ to human adipose-derived stem cells (hASCs), a subpopulation of MSCs. Furthermore, after the exposure we followed the cells for 15 days to evaluate their ability to recover their physiological functions.

hASCs are found in the stromal vascular fraction of adipose tissue, which is easily accessible in large quantities by using a minimally invasive harvesting procedure [16]. In addition, hASCs seem to be as effective and, in some cases even more suitable, than bone marrow-derived MSCs in clinical applications [17,18].

The results presented in this paper aim to add new information to the body of knowledge about the potential recovery of stem cells exposed to NPs.

\section{Materials \& methods}

\section{Nanoparticles}

Cobalt oxide nanopowder $\left(\mathrm{Co}_{3} \mathrm{O}_{4}\right.$-NPs, purity $99.8 \%$, aerodynamic particle size $\left.<50 \mathrm{~nm}\right)$ was purchased from Sigma-Aldrich (Milan, Italy). Cobalt zerovalent nanopowder (zCo-NPs purity $99.8 \%$, aerodynamic particle size $<28 \mathrm{~nm}$ ) was purchased from IOLITEC (Heilbronn, Germany).

\section{Dissolution of NPs in culture medium}

zCo-NPs and $\mathrm{Co}_{3} \mathrm{O}_{4}$-NPs were suspended in $40 \mathrm{ml}$ of complete medium (DMEM:DMEM/F12 1:1 [Sigma Aldrich], supplemented with $2 \mathrm{mM} \mathrm{L-Gln,} 1 \%$ penicillin-streptomycin, $0.1 \%$ gentamicin and $10 \%$ fetal bovine serum (FBS) at a concentration of $10 \mathrm{mg} / \mathrm{ml}$ as cobalt ( $400 \mathrm{mg}$ of zCo-NPs and $544 \mathrm{mg}$ of $\mathrm{Co}_{3} \mathrm{O}_{4}-\mathrm{NPs}$ ), placed in an ultrasonic bath for about $15 \mathrm{~min}$, transferred to petri dishes, and incubated at $37^{\circ} \mathrm{C}$ and $5 \% \mathrm{CO}_{2}$ under continuous shaking. After $24 \mathrm{~h}$, the NPs were removed by a magnet, the supernatants were centrifuged three-times at $15,500 \times g$ for $15 \mathrm{~min}$ at room temperature (RT), thereafter at $300,000 \times g$ for $2 \mathrm{~h}$ at $4^{\circ} \mathrm{C}$. The samples were filtered through a $0.22-\mu \mathrm{m}$ filter and then split into aliquots of $10 \mathrm{ml}$ and stored at $-80^{\circ} \mathrm{C}$ until analysis. To evaluate the variability due to different preparations, we performed two independent experiments. The presence of Co was also evaluated in complete culture media without NPs.

Solubilized metal evaluation by inductively coupled plasma optical emission spectrometry

The amount of Co ions in NP-free filtrates was analyzed by Optima ${ }^{T M} 7000$ DV inductively coupled plasma optical emission spectrometry (ICP-OES; Perkin-Elmer, CA, USA). Prior to measurement, the filtered supernatants were transferred to clean tubes for acid digestion. Thereafter, $4 \mathrm{ml}$ of aqua regia $\left(37 \% \mathrm{HCl}\right.$ and $65 \% \mathrm{HNO}_{3}$ in $3: 1$ ratio) were added to $1 \mathrm{ml}$ of each sample and the acidified samples were heated following a two-stage digestion program using a ETHOS TC microwave (Milestone Inc., Sorisole, Italy). The heating procedure consisted of a first step of $10 \mathrm{~min}$ at $1000 \mathrm{~W}$ to reach a temperature of $200^{\circ} \mathrm{C}$ and a second step of $15 \mathrm{~min}$ at $1000 \mathrm{~W}, 200^{\circ} \mathrm{C}$. After cooling, the digested samples were transferred to $15-\mathrm{ml}$ ICP-OES analysis tubes and diluted to $10 \mathrm{ml}$ with MilliQ water (Millipore, Milan, Italy). The analyses were conducted on samples from two independent bioassays, and each measurement was replicated three-times.

Samples

The five subjects involved in this research gave their informed consent for inclusion before they participated in the study. The procedures were performed in accordance with the Ospedale di Circolo Ethical Committee and the European Communities Council Directive of EU/63/2010. hASCs were isolated from mammary adipose tissue obtained from five healthy women who underwent surgery for gigantomastia at the 'Ospedale di Circolo', Varese, Italy. Average age of the subjects was $43 \pm 4$ years. They had not experienced any great weight loss from dieting (BMI was from 18.8 to $29 \mathrm{~kg} / \mathrm{m}^{2}$ ), were nonsmokers, had no history of metabolic disorders and were not taking medications at the time of the medical procedure. Owing to the gigantomastia, we were able to obtain large amounts of adipose tissue from the same depot; furthermore, the rigorous selection of the subjects insured that specimens were of good quality and rich in hASCs. 
hASC isolation \& culture

hASCs were isolated according to the Gronthos and Zannettino protocol modified in our laboratory [16]. Briefly, the stromal vascular fraction was obtained by collagenase type II digestion (Sigma Aldrich) at $37^{\circ} \mathrm{C}$ for $1 \mathrm{~h}$ in agitation. Stromal vascular fraction was filtered $(100 \mu \mathrm{m}$ cell strainers) and centrifuged at $180 \times \mathrm{g}$ for $10 \mathrm{~min}$; the resulting pellet was washed with erythrocyte lysis buffer (154 mM NH $4 \mathrm{Cl}, 10 \mathrm{mM} \mathrm{KHCO}_{3}$ and $1 \mathrm{mM}$ EDTA), then seeded in T25 flasks maintained at $37^{\circ} \mathrm{C}, 5 \% \mathrm{CO}_{2}$. After $6 \mathrm{~h}$, nonattached cells were removed. Cells were grown in DMEM:DMEM/F12 1:1, supplemented with $2 \mathrm{mM} \mathrm{L-Gln,} 1 \%$ penicillin-streptomycin, $0.1 \%$ gentamicin and $10 \%$ FBS. hASCs were subsequently cultured in T75 flasks and used at fifth confluence for all experiments.

\section{hASC characterization}

Cells were characterized by cytofluorimetric analysis, as previously described by Cherubino et al. [16], immunostaining and qPCR.

For immunostaining, CD44 antibody was used as a stemness marker and adiponectin receptor 1 (ADIPOR1) antibody as an adipogenic differentiation marker. hASCs were seeded on coverslips and incubated for $24 \mathrm{~h}$ at $37^{\circ} \mathrm{C}, 5 \% \mathrm{CO}_{2}$; cells were then fixed with $4 \%$ paraformaldehyde for $10 \mathrm{~min}$ at RT and permeabilized with $0.1 \%$ TWEEN-20 in phosphate-buffered saline (PBS) solution supplemented with $2 \%$ bovine serum albumine for $30 \mathrm{~min}$ at RT. After permeabilization, cells were incubated overnight at $4^{\circ} \mathrm{C}$ with primary antibody anti-CD 44 diluted 1:50 (Abcam, Milan, Italy) or with anti-ADIPOR1 diluted 1:100 (Abcam). Cells were then incubated for $1 \mathrm{~h}$ with anti-goat secondary polyclonal antibody conjugated with Alexa Fluor ${ }^{\circledR} 488$ and diluted 1:500 (Abcam) for CD44 antibody or with secondary anti-donkey polyclonal antibody conjugated with Alexa Fluor 647 diluted 1:600 (Abcam, Milan, Italy) for ADIPOR1 antibody. For nuclear staining, cells were treated with $1 \mu \mathrm{g} / \mathrm{ml} \mathrm{4',6-}$ diamidino-2-phenylindole diluted 1:5000 for $5 \mathrm{~min}$ at RT. Finally, cells were observed under a Zeiss Axio Imager Z1 fluorescence microscope (Carl Zeiss AG, Werk Göttingen, Germany), equipped with an AxioCam digital camera (Zeiss, Jena, Germany).

For qPCR, CD44 and CD90 genes were used as positive stemness markers, while FABP4, ACRP30 and ACSS2 genes were taken as differentiation markers. Values, derived from the five subjects, were normalized with two reference genes (GAPDH and $\beta 2 \mathrm{~m}$ ) according to the method of Palombella et al. [19] and quantified by using the $2^{-\Delta \mathrm{Ct}}$ method. Each experiment was repeated three-times.

\section{RNA extraction \& qPCR}

Total RNA was isolated using the MiniPrep kit (ZymoResearch, Italy) according to the manufacturer's protocol. The extracted RNA was quantified by the QuantiFluor ${ }^{\circledR}$ RNA System (Promega, WI, USA) and assessed by $1 \%$ gel electrophoresis to verify the integrity. The RNA was reverse transcribed using the iScript ${ }^{\top M} \mathrm{cDNA}$ Synthesis Kit (BioRad, Italy) and the cDNA was stored at $-20^{\circ} \mathrm{C}$ until use. qPCR was conducted using iTaqTM Universal SYBR $^{\circledR}$ Green Supermix (BioRad). The Beacon Designer Program (BioRad) was used to design specific primers; the sequences are shown in Table 1.

Each sample was prepared as reported in Rossi et al. [20]. Here, $1 \mu \mathrm{l}(5 \mathrm{ng})$ of cDNA, $1 \mu \mathrm{l}$ of forward and reverse primer mix $(6 \mu \mathrm{M}), 7.5 \mu \mathrm{l}$ of SYBR Green Supermix $(2 \times)$ and water to a final volume of $15 \mu$ were mixed and placed in the CFX 96 Thermocycler (BioRad). A thermal cycle comprised the following settings: 5 min at $95^{\circ} \mathrm{C}$, $10 \mathrm{~s}$ at $95^{\circ} \mathrm{C}$ and $30 \mathrm{~s}$ at $60^{\circ} \mathrm{C}$ for 40 cycles.

Based on our previous experience and published data [3,21], we selected HSP70, MT2A, MLL, SDHB1, CASP3, QSEC1, and VMP1 as target genes to determine gene expression. Values, derived from five subjects, were normalized with three reference genes, GAPDH, $\beta 2 m$ and RPL13 according to the method of Palombella et al. [19] and quantified by using the $2^{-\Delta \Delta \mathrm{Ct}}$ method. Each experiment was repeated three times.

\section{Cell exposure for toxicity, recovery \& gene expression}

For all the experiments, cells were maintained as reported in the section 'hASC isolation and culture'.

For cytotoxicity, 500 cells were seeded into a 96-well plate and then cultivated for $24 \mathrm{~h}$ at $37^{\circ} \mathrm{C}$ in $5 \%$ of $\mathrm{CO}_{2}$ to equilibrate and become attached before treatment. Cells were then exposed for $3 \mathrm{~h}$ at increasing amounts of dissolved Co (resulting from the dissolution of zCo-NPs in culture medium), corresponding to 0, 1.06, 2.12, 4.24, 6.36 and $8.48 \mu \mathrm{g}$ of Co $(200 \mu \mathrm{l}$ final volume). In parallel, cells were also exposed to the same Co amount of zCo-NPs and $\mathrm{CoCl}_{2}$ freshly prepared in culture medium. NP suspensions were prepared before each treatment using an ultrasonic bath for $15 \mathrm{~min}$ to disperse NPs in culture medium. After exposure, the plate was equilibrated at RT for $30 \mathrm{~min}$ and 


\begin{tabular}{|c|c|c|c|c|}
\hline Gene name & & Sequence $5^{\prime}-3^{\prime}$ & Melting temperature $\left({ }^{\circ} \mathrm{C}\right)$ & Accession number \\
\hline \multirow[t]{2}{*}{ GAPDH } & FW Primer & СCCTTCATTGACCTCAACTAC & 61.5 & M17851.1 \\
\hline & Rev Primer & CATTGATCACAAGCTTCCCG & 61.6 & \\
\hline \multirow[t]{2}{*}{$\beta 2 m$} & FW Primer & TTCTGGCCTGGAGGCTATC & 60.0 & AB021288.1 \\
\hline & Rev Primer & TCAGGAAATTTGACTTTCCATTC & 59.0 & \\
\hline \multirow[t]{2}{*}{ RPL13 } & FW Primer & TATGAGTGAAAGGGAGCC & 60.0 & NM_012423.3 \\
\hline & Rev Primer & ATGACCAGGTGGAAAGTC & 60.0 & \\
\hline \multirow[t]{2}{*}{$C D 44$} & FW Primer & GCAGTCAACAGTCGAAGAAG & 62.9 & AY101192.1 \\
\hline & Rev Primer & GTCCTCCACAGCTCCATT & 62.9 & \\
\hline \multirow[t]{2}{*}{ CD90 } & FW Primer & СТCTACTTATCCGCCTTCACT & 62.9 & NM_006288.4 \\
\hline & Rev Primer & CGTTCTGGGAGGAGATGG & 63.0 & \\
\hline \multirow[t]{2}{*}{ FABP4 } & FW Primer & AAGTCAAGAGCACCATAACCT & 63.3 & NM_001442.2 \\
\hline & Rev Primer & GCATTCCACCACCAGTTTATC & 63.4 & \\
\hline \multirow[t]{2}{*}{ ACRP3O } & FW Primer & GGAAGGAGAGCGTAATGGA & 62.7 & NM_004797.3 \\
\hline & Rev Primer & AGTTGGTGTCATGGTAGAGAA & 62.7 & \\
\hline \multirow[t]{2}{*}{ ACSS2 } & FW Primer & ATACAAGGTGACCAAGTTCTACA & 63.3 & NM_018677.3 \\
\hline & Rev Primer & GTGACAGGCTCATCTCCAA & 63.3 & \\
\hline \multirow[t]{2}{*}{ HSP7O } & FW Primer & TGACAACAGGCTGGTGAA & 63.0 & M11717.1 \\
\hline & Rev Primer & CGCTTGTTCTGGCTGATG & 62.9 & \\
\hline \multirow[t]{2}{*}{ IQSEC1 } & FW Primer & GTCGGTTGGTCTGCTACT & 62.9 & NM_001134382.3 \\
\hline & Rev Primer & AGGTCGTTGAACAGGAAGAT & 62.9 & \\
\hline \multirow[t]{2}{*}{ MT2A } & FW Primer & GCAAATGCAAAGAGTGCAAATG & 64.2 & NM_005953.5 \\
\hline & Rev Primer & ACTTGGCACAGCCCACAG & 66.9 & \\
\hline \multirow[t]{2}{*}{$S D H B 1$} & FW Primer & GGAAGGCAAGCAGCAGTAT & 64.3 & NM_003000.2 \\
\hline & Rev Primer & ACAGCAGGCACAGAGAATG & 64.2 & \\
\hline \multirow[t]{2}{*}{ MLL } & FW Primer & GAGGCTTAGGAATCTTGACTT & 61.3 & AF232001.1 \\
\hline & Rev Primer & CAACAGACTTGGCAATACAC & 61.1 & \\
\hline \multirow[t]{2}{*}{ CASP3 } & FW Primer & TGGACTGTGGCATTGAGAC & 63.9 & NM_004346.4 \\
\hline & Rev Primer & CCAGGTGCTGTGGAGTATG & 64.0 & \\
\hline \multirow[t]{2}{*}{ VMP1 } & FW Primer & TCGGTACAGCAATCGGAGAG & 65.6 & NM_030938.5 \\
\hline & Rev Primer & GCATGTTCCAGCATCTCTTCAA & 65.4 & \\
\hline
\end{tabular}

the culture medium was replaced with 1:1 PBS and CellTiter-Glo ${ }^{\circledR}$ Luminescent Cell Viability Assay (Promega, Milano, Italy). To adopt the most suitable assay, an interference testing evaluation was performed previously. Data from our laboratory (UNPUBLISHED DATA) and from the literature [22-25] recommended introducing additional washing steps when an MTT assay is used or to prefer a fluorescence or photoluminescence assay. CellTiter-Glo is based on the luciferase reaction to quantify the amount of ATP present in cells; the luminescent signal is directly proportional to the number of viable cells. The plate was stirred for $2 \mathrm{~min}$ and left at RT for $10 \mathrm{~min}$ before detecting the luminescence using the Infinite F200 plate reader (Tecan Group, Männedorf, Switzerland).

To evaluate cell recovery capability, 1500 cells were seeded into a 24-well plate and then exposed for $3 \mathrm{~h}$ at the nominal concentration of $2 \mu \mathrm{g} / 400 \mu \mathrm{l}$ of working volume $(86 \mu \mathrm{M})$ of Co contained in $\mathrm{Co}_{3} \mathrm{O}_{4}-\mathrm{NPs}$, zCoNPs or $\mathrm{CoCl}_{2}$. The dose and the exposure time used in this experiment caused cell mortality not higher than 20-30\% (EC20). After the exposure, treatment solutions were removed, cells were washed with PBS and fresh medium containing RealTime-Glo ${ }^{T M}$ MT reagent (Promega) was added. This assay is a nonlytic, homogeneous, bioluminescent method to estimate cell viability in real time by measuring the reducing potential of cells and, thus, metabolism. Viable cells reduce the prosubstrate to generate a substrate for luciferase. The luminescent signal was recorded using the Infinite F200 plate reader every $24 \mathrm{~h}$ for 7 days. All the experiments were run in triplicate and repeated three-times.

For gene expression, cells were grown in a T75 flask until the fifth confluence were exposed to zCo-NPs, Co was dissolved from zCo-NPs and $\mathrm{CoCl}_{2}$ at the EC20. After $3 \mathrm{~h}$, the cells were collected for RNA extraction. 

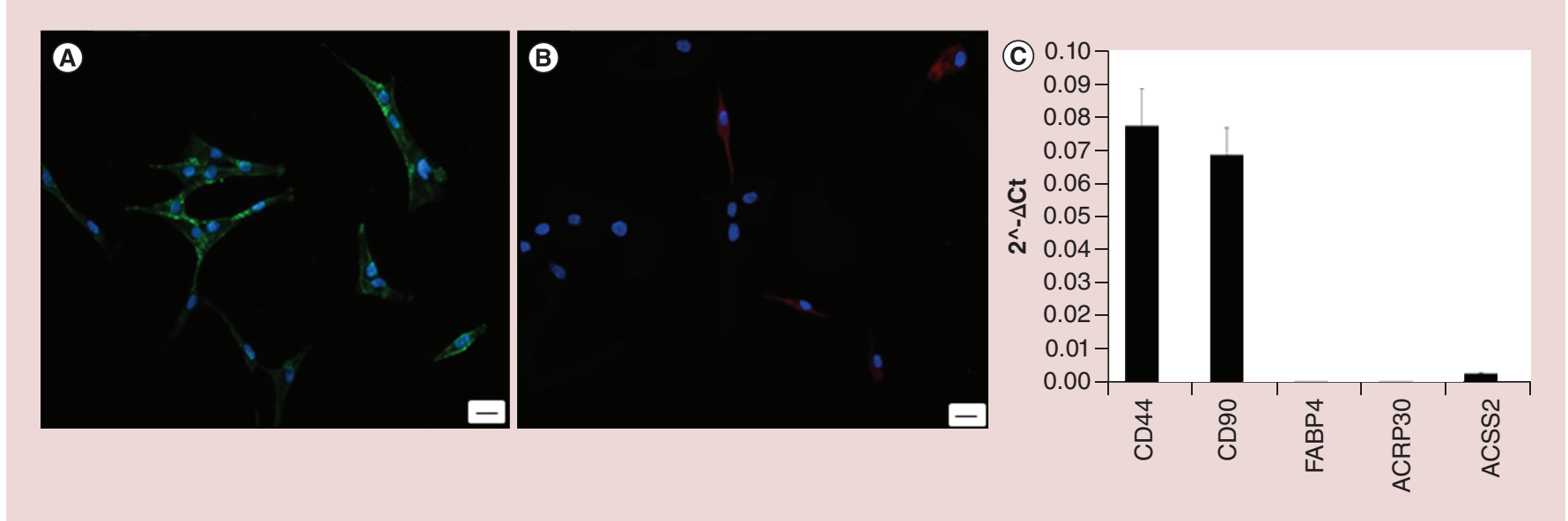

Figure 1. Human adipose-derived stem cells characterization. (A) CD44 antibody-positive cells, Alexa Fluor ${ }^{\circledR} 488$ dye. (B) ADIPOR1 antibody-positive cells, Alexa Fluor 647 dye. Nuclei stained with 4',6-diamidino-2-phenylindole. Scale bar: $20 \mu \mathrm{m}$. (C) qPCR of stemness genes CD44 and CD90, and adipogenic genes FABP4, ACRP30 and ACSS2. Values, normalized with the reference genes GAPDH and $2 \beta m$, are expressed as mean \pm standard deviation of five subjects.

\section{Uptake \& morphology}

These experiments were performed in steady state. For optical microscopy 5000 cells were cultured in DMEM on $24 \mathrm{~mm}^{2}$ coverslips into 6-well culture plates, cultivated at $37^{\circ} \mathrm{C}$ in $5 \% \mathrm{CO}_{2}$, and then exposed to EC20 of $\mathrm{Co}_{3} \mathrm{O}_{4}$-NPs or zCo-NPs for $3 \mathrm{~h}$. After the exposure, NPs were removed; cells were washed with PBS and, after an appropriated time $(0,5,10$ or 15 days), fixed for 10 min with $100 \%$ methanol at RT, then stained with hematoxylin-eosin solution according to standard procedures.

For Oil Red O staining after exposure and 15 days of recovery, cells were washed with PBS, fixed with $10 \%$ formalin for $30 \mathrm{~min}$ at RT, then rinsed twice with water and incubated for $5 \mathrm{~min}$ at RT with $60 \%$ isopropanol. After isopropanol's removal, Oil Red O working solution (Sigma-Aldrich) was added for $10 \mathrm{~min}$ at RT. Cells were then washed twice with water and slides were mounted using Eukitt (Bio-Optica, Milano, Italy).

For transmission electron microscopy (TEM) analysis, 100,000 cells were cultured in a T25 flask and treated as previously described. At the end of the experiment the cells were harvested, fixed and embedded as previously described [10], and finally observed by using a Morgagni electron microscope (Philips, Eindhoven, The Netherlands) operating at $80 \mathrm{kV}$.

\section{Statistical analysis}

For qPCR, data analysis was performed by Student's t-test on the $\Delta \mathrm{Ct}$ values of exposed cells versus unexposed cells, used as control. Data from five samples were expressed as mean values ( \pm standard error) and were considered significantly different at $\mathrm{p}<0.05$.

\section{Results}

Nanoparticle characterization

Characterization of the NPs used in this research was reported in our previous publications: Palombella et al. [10] for $\mathrm{zCoNPs}$ and Papis et al. [9] for $\mathrm{Co}_{3} \mathrm{O}_{4}$-NPs.

\section{hASC characterization}

Immunostaining and qPCR analysis (Figure 1) indicated that the hASCs used are mostly stem cells. The majority of the cells are CD44 positive (Figure 1A); conversely, ADIPOR1-positive cells are rarely visible (Figure 1B). qPCR outcome, reported in Figure 1C, confirmed the immunostaining results, showing high mRNA expression of stemness genes (CD44 and CD90) and very low expression of adipogenic genes (FABP4, ACRP30 and ACSS2). Taken together, these results support those previously obtained by FACS analysis, in which the expression of CD44, CD90, CD105 and HLA class I markers represented a characteristic of the entire hASC population, thus operationally defining the homogeneity of the cells under study [16]. 

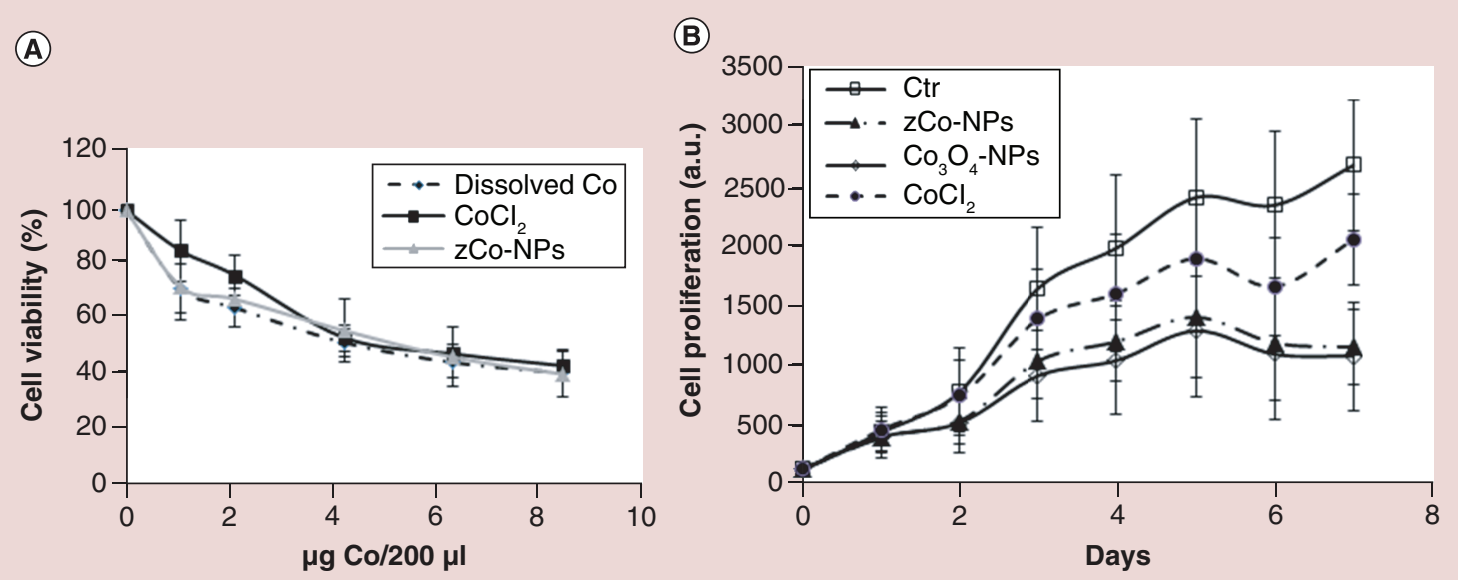

Figure 2. Human adipose-derived stem cells viability and proliferation. (A) Cell viability of human adipose-derived stem cells after $3 \mathrm{~h}$ exposure to increasing concentrations of dissolved zerovalent Co-NPs (dissolved Co), of zCo-NPs or $\mathrm{CoCl}_{2}$. (B) Time recovery capability of cells exposed for $3 \mathrm{~h}$ at the nominal concentration of $1 \mu \mathrm{g}$ of Co contained in $\mathrm{CO}_{3} \mathrm{O}_{4}$-NPs, Co-NPs or $\mathrm{CoCl}_{2}(200 \mu \mathrm{l}$ final volume). Results are expressed as increase of cell number. Data are expressed as mean values \pm standard error $(n=5)$.

Ctr: Control; zCo-NP: Zerovalent cobalt-nanoparticle.

\section{Dissolution of NPs in culture medium}

Since the aim of this study was to evaluate the effect of ions released from NPs suspended in a culture medium, we used saturated solutions to guarantee the maximum amount of NPs dissolved in the culture medium. ICP-OES analysis detected $424 \mathrm{ppm}(\mathrm{mg} / \mathrm{l})$ of $\mathrm{Co}$ for zCo-NPs and only $3.32 \mathrm{ppm}$ for $\mathrm{Co}_{3} \mathrm{O}_{4}$-NPs.

\section{Cytotoxicity \& recovery}

Due to the very low dissolution of $\mathrm{C}_{3} \mathrm{O}_{4}-\mathrm{NPs}$, viability experiments were only performed on Co derived from the dissolution of zCo-NPs in culture medium, freshly made $\mathrm{zCo}-\mathrm{NP}$ suspension and $\mathrm{CoCl}_{2}$ solution (however, as reported in Papis et al. [21], the $\mathrm{Co}_{3} \mathrm{O}_{4}$-NP toxicity evaluated on two different cell lines in the same experimental setting was similar). The results, shown in Figure $2 \mathrm{~A}$, demonstrated good overlap among all the considered treatments, confirming that, under these experimental conditions, cell toxicity is prevalently due to Co ions. Figure 2B, reporting the results of cell recovery that was monitored for 7 days after $3 \mathrm{~h}$ exposure at EC20, indicated that although all the samples reached steady step (plateau) at day 5 , the proliferation curve is different according to the treatment. In the control sample (Ctr), cell viability increased faster than in the exposed cells. Interestingly, cells exposed to $\mathrm{CoCl}_{2}$ recovered more readily than those exposed to $\mathrm{zCo}-\mathrm{NPs}$ and $\mathrm{Co}_{3} \mathrm{O}_{4}-\mathrm{NPs}$, which displayed similar behavior.

\section{Cellular uptake \& morphology}

Figure 3 shows optical microscopy images concerning the morphology and uptake of cells not exposed (Figure 3AD) and exposed to EC20 (Figure 3E-N). In detail, Figure 3E \& I showed that, after $24 \mathrm{~h}$ of exposure, the NPs are internalized by the cells and stored in cytoplasmic vesicles. Figure $3 \mathrm{~F}-\mathrm{H}$ clearly displayed that, despite their removal, $\mathrm{Co}_{3} \mathrm{O}_{4}$-NPs remained inside the cell for the entire considered time. Conversely, 10 days after exposure, no zCo-NPs were found in almost all the observed cells. After 15-day recovery, cells stained with Oil Red O (Figure 4) did not show particular differences in their morphology after being exposed (Figure 4B \& C) and not exposed (Figure 4A). Interestingly, as shown in Figure 4B, cells are able to proliferate even in the presence of $\mathrm{Co}_{3} \mathrm{O}_{4}-\mathrm{NPs}$. Most of these observations were confirmed by TEM analysis; in fact, as depicted in Figure 5A-D, the morphology of unexposed cells is that expected for hASCs embedded for TEM observation. The cell body was rounded, the nucleus was large, indented and eccentric, with abundant euchromatin and a prominent nucleolus; lysosomes, lipid droplets and vacuoles of different sizes were present in the cytoplasm and the cell membrane was characterized by some pseudopodia-like protrusions [10]. Notwithstanding the low cell mortality, the EC20 used in these experiments provoked some ultrastructural modifications, even causing severe cellular damage that, probably, depended on NPs. 


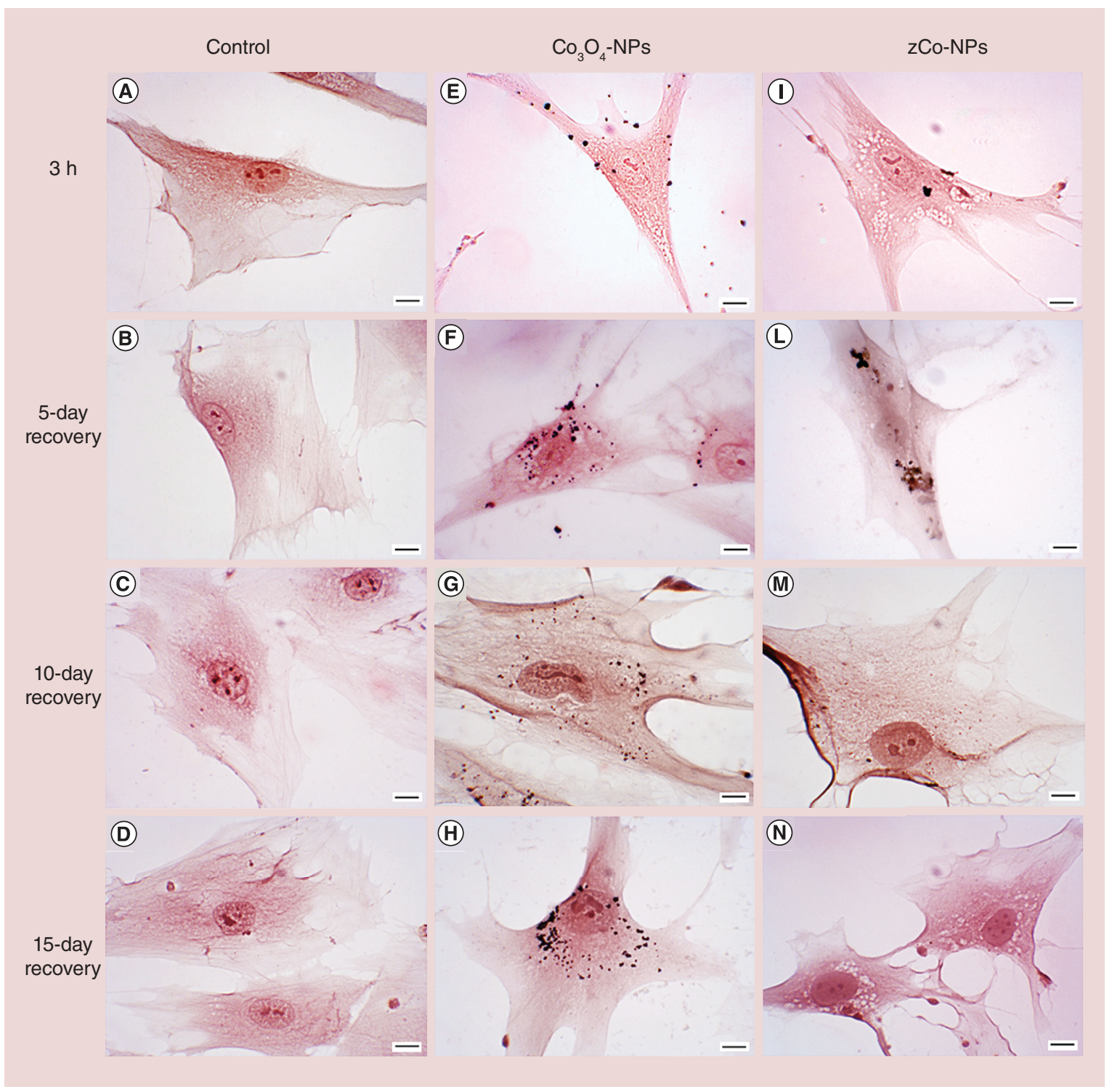

Figure 3. Representative pictures, stained with hematoxylin-eosin. (A-D) Unexposed cells; $(\mathrm{E}-\mathrm{H}) \mathrm{Co}_{3} \mathrm{O}_{4}-\mathrm{NPs}$ exposed cells and (I-N) zerovalent cobalt-NPs exposed cells. Within $3 \mathrm{~h}$, the NPs were internalized by the cells and stored in cytoplasm vesicles $(\mathbf{E} \& \mathbf{I})$. After 5 -day recovery NPs were still present $(\mathrm{F} \& \mathrm{~L})$. After 10 -day recovery, $\mathrm{Co}_{3} \mathrm{O}_{4}-\mathrm{NPs}$ remained inside the cells (G), whereas no zCo-NPs were noticed (M). Same conditions were observed after 15-day recovery (H \& N). Scale bar: $20 \mu \mathrm{m}$.

zCo-NP: Zerovalent cobalt-naanoparticle.

As shown in Figure 5E-N, there are more pseudopodia-like protrusions, vacuole vesicles, and lysosomes of different sizes in the exposed cells than observed in unexposed ones (Figure 5A-D); furthermore, several mitochondria have lost their organization (Figure 5I). Vacuoles, often containing low electron-dense material, were present in the cytoplasm of the exposed samples, including those observed immediately after $3 \mathrm{~h}$ of exposure (Figure 5E $\&$ I). These characteristics confirmed that NPs were massively internalized as agglomerated mainly by endocytic mechanisms. Once internalized, NPs remained inside the cytoplasm up to 5 days (Figure 5F \& L). As depicted in Figure $5 \mathrm{G} \& \mathrm{H}$, from the 10th day after the exposure, NPs remained exclusively in the cells exposed to $\mathrm{Co}_{3} \mathrm{O}_{4}-\mathrm{NPs}$. In contrast, as shown in Figure $5 \mathrm{M} \& \mathrm{~N}$, no NPs were found in those cells exposed to zCo-NPs. Although no patchy chromatin distribution was observed in treated cells, the rough endoplasmic reticulum and Golgi apparatus did not appear to be particularly affected; some blebbing cells (an example in Figure $5 \mathrm{~N}$ ), characteristic of an apoptotic state, are present. 


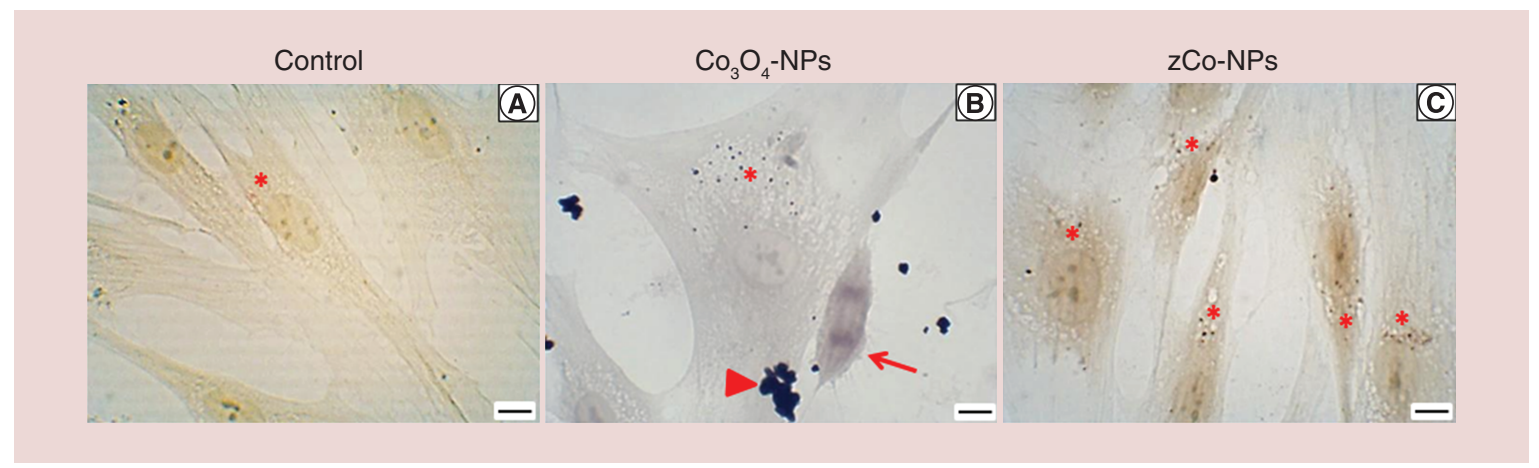

Figure 4. Representative pictures of human adipose-derived stem cells, stained with Oil Red $\mathrm{O}$ staining after 15-day recovery. (A) Unexposed cells, (B) cells exposed to $\mathrm{Co}_{3} \mathrm{O}_{4}-\mathrm{NPs}$, (C) cells exposed to $\mathrm{zCo}$-NPs. Interesting is the presence of cells able to proliferate (arrow); lipid droplets (*). Arrow: $\mathrm{CO}_{3} \mathrm{O}_{4}$-NPs. Scale bar: $20 \mu \mathrm{m}$.

zCo-NP: Zerovalent cobalt-nanoparticle.

\section{Gene expression}

The relative gene expression of the examined genes (HSP70, MT2A, MLL, SDHB1, CASP3, IQSEC1 and VMP1) is reported in Figure 6. At the amount of Co used in this research, only the expression of the VMP1 of those samples exposed to dissolved $\mathrm{zCo}$-NPs appeared significantly downregulated $(\mathrm{p}<0.05)$. For the other genes, we only observed a slight modification in the exposed versus the unexposed cells. Generally, the response did not seem to be dependent on the Co formulation.

\section{Discussion}

The toxic potential of NPs is a matter of concern due to their own distinctive physico-chemical characteristics and the ability to interact with living organisms and complex biological environments. Therefore, published experimental data in the nanotoxicology field have steadily increased since first appearing in 1990, and markedly during the last decade.

Little is known about how NPs are eliminated from the cells and what happens after single or repeated exposures [26]. In addition, the need to prolong the retention time of internalized NPs in the body to improve their efficacy in imaging, drug delivery and theranostic applications [27] increases the possibility that NPs come in contact with cells, including stem cells, which are more sensitive. It is, therefore, important to determine a concentration range for NPs that is safe and can be used without causing irreversible cell damage. Therefore, we focused our study on the effect of Co-NPs and Co ions on hASCs, the most abundant stem cells residing in the body [28].

Our results on cell viability during the recovery phase demonstrated that, if not compromised by mechanical damage due to the massive NP internalization [29], the function of most of the hASCs exposed to zCo-NPs and $\mathrm{Co}_{3} \mathrm{O}_{4}$-NPs returns to normal. However, when cell toxicity develops, it is probably due to both NPs as such and to the ions released by dissolution in the culture medium or after entering the cell. It is recognized that dissolution is one of the main sources of NP toxicity, and although it can take considerable time to perform such a study and it is complicated by issues such as particle separation from solution, it represents a key aspect of nanotoxicology [30]. Co ions are involved in several cellular processes, for example, in the induction of hypoxia by the increase in the inducible HIF-1 $\alpha$, which, in turn, could be the cause of reduced cell proliferation [31]. Some authors [32,33] reported that at a concentration of $100 \mu \mathrm{M}$, like used in our experiments, Co ions may induce reactive oxygen specie synthesis, which is responsible for DNA damage that, in turn, can alter the synthesis and the activity of many signaling proteins involved in the stress response, such as cell proliferation and apoptosis induction. qPCR experiments did not reveal any important involvement in mRNA expression of those genes susceptible to metal exposure and implicated in general (HSP70, MT2A) or in specific cell processes (SDHB1, MLL, CAS3, IQSEC1). However, except for $M T 2 A$, a general downregulation was found in all the examined genes from exposed samples. VMP1 is a protein localized in the autophagosomal membrane and associated with autophagy, membrane traffic and cell adhesion [34,35]. Cells deficient in VMP1 display defects in autophagosome biogenesis or maturation as well as in the secretory pathway [36]. Notwithstanding its involvement in such important functions and preliminary indications of its responsiveness to metal exposure [37], VMP1 was only significantly downregulated in those cells exposed to the medium containing dissolved zCo-NPs. Under the experimental conditions in our study, we found 


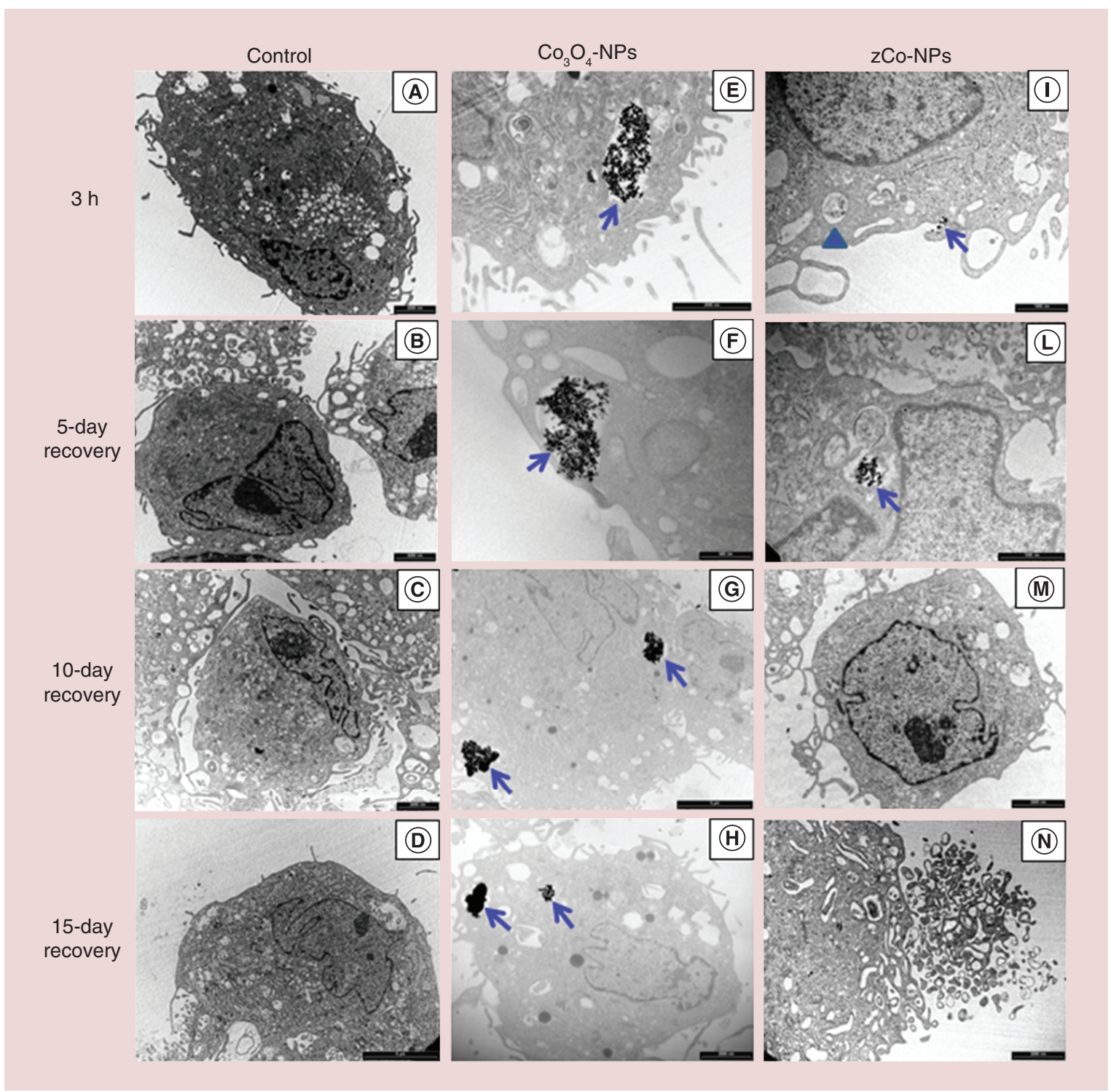

Figure 5. Transmission electron microscopy analysis. Representative pictures of unexposed (A-D),

$\mathrm{CO}_{3} \mathrm{O}_{4}$-NPs-exposed (E-H) and zCo-NPs-exposed human adipose-derived stem cells (I-N). After $3 \mathrm{~h}$ of exposure, NPs were internalized (arrows, E \& I). After 5-day recovery, NPs were still present (arrows, F \& L). After 10-day recovery, $\mathrm{Co}_{3} \mathrm{O}_{4}-\mathrm{NPs}$ were still present (arrows, G). Differently, no Co-NPs were found (M). Same conditions were observed after 15-day recovery $(\mathbf{H} \& \mathbf{N})$. Regardless of the NPs, cell membrane presented pronounced pseudopodia-like protrusions and several empty vacuoles (E-N). Arrowhead showed a disorganized mitochondria (I). Scale bars: (A, B, C, E, H, M \& N) $2 \mu \mathrm{m}$; (D \& G) $5 \mu \mathrm{m}$; (F) $500 \mathrm{~nm}$; (I \& L) $1 \mu \mathrm{m}$. zCo-NP: Zerovalent cobalt-nanoparticle.

a nonsignificant decrease in $S D H B 1 \mathrm{mRNA}$ expression, indicating that, in general, mitochondrial function is not perturbed; however, TEM analysis indicated that mitochondria appeared disorganized, which may be due to impairment of other mechanisms that do not directly involve SDHB1 mRNA expression.

Other toxic effects of $\mathrm{Co}$ ions could be due to its competition with $\mathrm{Ca}^{2+}$ in the cell-signaling and -binding proteins [38]. Although the amount of $\mathrm{Co}^{2+}$ released by $\mathrm{Co}_{3} \mathrm{O}_{4}-\mathrm{NPs}$ in the medium was very low [9,39], $\mathrm{Co}_{3} \mathrm{O}_{4}-\mathrm{NP}$ toxicity was recognized and presumably caused by the fast cell internalization through endocytosis, via the clathrindependent pathway $[9,15,29,39]$. Once inside the cells, $\mathrm{Co}_{3} \mathrm{O}_{4}$-NPs are preferably stored in endocytic vesicles, which, in turn, are recruited by lysosomes whose acidic $\mathrm{pH}$ can progressively solubilize the NPs that continuously release ions over a long period. 


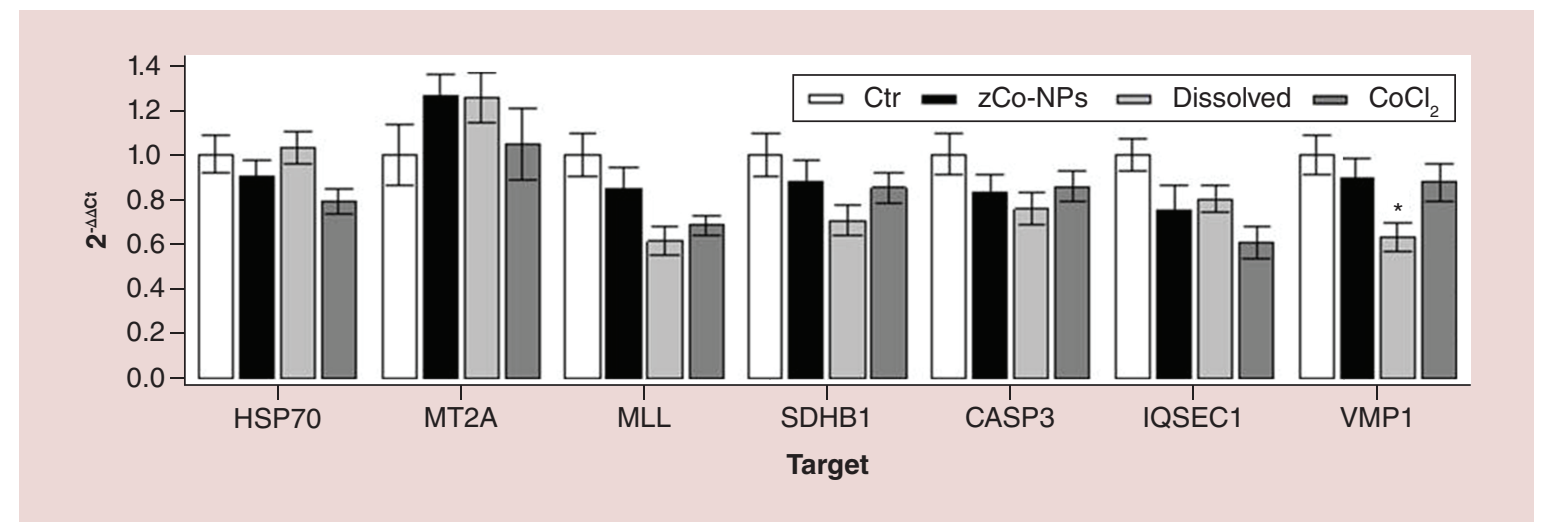

Figure 6. Gene expression. mRNA-relative expression of HSP70, MT2A, MLL, SDHB1, CASP3, IQSEC1 and VMP1 genes in unexposed human adipose-derived stem cells (control, white bars), human adipose-derived stem cells exposed for $3 \mathrm{~h}$ to zerovalent cobalt-nanoparticles (black bars), dissolved zerovalent cobalt-nanoparticles (light gray bars) and $\mathrm{CoCl}_{2}$ (dark gray bars). Values are normalized with the reference genes GAPDH, $\beta 2 m$ and RPL13, and the expression has been reported as $2^{-\Delta \Delta \mathrm{Ct}}$ : data statistically significant according to Student's t-test.

$\mathrm{p}<0.05 ; \mathrm{n}=5$.

Ctr: Control; zCo-NP: Zerovalent cobalt-nanoparticle.

Interestingly, an old, established publication mentioned that, despite the proven competition of $\mathrm{Co}^{2+}$ with $\mathrm{Ca}^{2+}$, an extracellular increase in $\mathrm{Ca}^{2+}$ triggered a complete program of keratinocyte differentiation, whereas $\mathrm{Co}^{2+} \mathrm{did}$ not [40]. Our experiments with Oil Red O staining did not indicate that differentiation speeded up but did indicate that, occasionally, cells can also undergo mitosis in the presence of NPs, a circumstance already observed in cells exposed to $\mathrm{Fe}_{3} \mathrm{O}_{4}-\mathrm{NPs}$ [24]. In contrast, cell ultrastructure demonstrated that exposed cells, though alive, can display typical alterations of an early apoptotic state. As concerns cellular uptake, microscopic analysis confirmed that NP internalization was rapid, nonspecific and concentration dependent [29]. After 10 days from the exposure we were not able to detect $\mathrm{zCo}$-NPs inside the cells, which could be due to NP dissolution and NP clearance. Whereas relatively little effort has been made to investigate NP removal, it is known that it can be affected by multiple factors, including size, shape, chemical-physical surface characteristics and functionalization, which, in turn, influence the formation of aggregates (strongly bonded NPs) and/or agglomerates (loosely bonded NPs) [41,42]. Pham et al. [42] reported that if iron oxide nanoparticles are not stabilized appropriately, the particles may aggregate, impeding or slowing the clearance; these studies are of great interest, in particular when NPs are used as contrast agents.

\section{Conclusion}

Considering the exponential growth of production, use in nanomedicine and consequent discharge, NPs may easily enter the body. For this reason, it is important to know what happens once they are internalized by the cells, particularly in the case of stem cells as they are more sensitive. In this scenario, it is fundamental to consider NP dissolution and clearance. In this study, we addressed these aspects of nanotoxicology. The results of the present work suggested that, after a single NP exposure, cells may survive if they have not suffered any mechanical damage due to massive NP internalization. Gene expression appeared to show a general tendency to decrease; however, increased sample numbers for gene expression analysis to boost the statistical power would be required to ascertain whether this is indeed biologically relevant. Furthermore, once internalized, the two formulations displayed a different behavior, probably due to fast dissolution and clearance of $\mathrm{zCo}-\mathrm{NPs}$ in comparison with $\mathrm{Co}_{3} \mathrm{O}_{4}$-NPs.

This work did not examine all the cellular mechanisms in depth; however, it is helpful to become aware of exposure doses that are safe for humans and to understand the consequences of the particulate effects of the nonmetabolizable nanoparticles, which may persist inside the cell and act even for a long time.

\section{Future perspective}

This work is intended to provide guidance on determining the safety dose of exposure using NPs and to determine the fate of NPs once they are internalized by the cells. As numerous metal NPs are used in nanomedicine, ranging from iron, to zinc, cadmium and many others, it will be important to extend this type of study to other NPs and, insofar as possible, to investigate the cellular mechanisms in greater depth. 
Summary points

- Human adipose stem cells were used as a model to evaluate cobalt-nanoparticle (Co-NP) toxicity.

- Treatment has been conducted using EC20, an effective dose without causing high mortality.

- Evaluation of two different formulations of Co-NP was conducted; an aspect that should be taken into account when studying NP effects.

- The study was conducted by a multidisciplinary approach based on cell morphology, ultrastructure and gene expression.

- NP dissolution is different and dependent on NP formulation.

- After $24 \mathrm{~h}$ of Co-NPs exposure a negligible effect on gene expression was shown.

- Different Co-NPs can persist inside the cells for varying times.

- If not compromised by mechanical damage due to the massive NP internalization, the function of the human adipose-derived stem cells returns to normal.

Author contributions

M Borgese contributed in microscopy and PCR experiments, and in draft manuscript writing. F Rossi contributed in culture cell maintaining, cell viability and proliferation experiments, and in draft manuscript writing. P Bonfanti, A Colombo and P Mantecca did ICP-OES experiments and contribution in the revision of the manuscript. G Bernardini contributed in the revision of the manuscript. $\mathrm{R}$ Gornati did conceptual processing, design and planning of experiments, and revision of the manuscript.

Acknowledgments

The authors gratefully acknowledge 'Centro Grandi Attrezzature per la Ricerca Biomedica' Università degli Studi dell'Insubria for instrument availability and for hospitality.

Financial \& competing interests disclosure

This project has been supported by FAR (Fondo comune di Ateneo per la Ricerca 2017 to R Gornati and G Bernardini). The authors have no other relevant affiliations or financial involvement with any organization or entity with a financial interest in or financial conflict with the subject matter or materials discussed in the manuscript apart from those disclosed.

No writing assistance was utilized in the production of this manuscript.

Ethical conduct of research

The authors state that they have obtained appropriate institutional review board approval or have followed the principles outlined in the Declaration of Helsinki for all human or animal experimental investigations. In addition, for investigations involving human subjects, informed consent was obtained from the participants involved.

Open access

This work is licensed under the Attribution-NonCommercial-NoDerivatives 4.0 Unported License. To view a copy of this license, visit http://creativecommons.org/licenses/by-nc-nd/4.0/

\section{References}

Papers of special note have been highlighted as: $\bullet$ of interest; $\bullet \bullet$ of considerable interest

1. Kobayashi M, Shimizu S. Cobalt proteins. Eur. J. Biochem. 261(1), 1-9 (1999).

2. Leyssens L, Vinck B, Van Der Straeten C, Wuyts F, Maes L. Cobalt toxicity in humans - a review of the potential sources and systemic health effects. Toxicology 387, 43-56 (2017).

3. Gornati R, Pedretti E, Rossi F et al. Zerovalent Fe, Co and Ni nanoparticle toxicity evaluated on SKOV-3 and U87 cell lines. J. Appl. Toxicol. 36, 385-393 (2016).

4. Liu X, Qiu G, Li X. Shape-controlled synthesis and properties of uniform spinel cobalt oxide nanocubes. Nanotechnology 16, 3035 (2005).

5. Bedanta S, Barman A, Kleemann W, Petracic O, Seki T. Magnetic nanoparticles: a subject for both fundamental research and applications. J. Nanomater. 2013, 1-22 (2013).

6. Estelrich J, Sánchez-Martín MJ, Busquets MA. Nanoparticles in magnetic resonance imaging: from simple to dual contrast agents. Int. J. Nanomedicine 10, 1727-1741 (2015).

7. Zanella D, Bossi E, Gornati R, Bastos C, Faria N, Bernardini G. Iron oxide nanoparticles can cross plasma membranes. Sci. Rep. 7(1), 1-10 (2017). 
8. Bossi E, Zanella D, Gornati R, Bernardini G. Cobalt oxide nanoparticles can enter inside the cells by crossing plasma membranes. Sci. Rep. 6, 1-9 (2016).

-• Helps in understanding the nanoparticles cell internalization by independent endocytosis route.

9. Papis E, Rossi F, Raspanti M et al. Engineered cobalt oxide nanoparticles readily enter cells. Toxicol. Lett. 189, 253-259 (2009).

10. Palombella S, Pirrone C, Rossi F et al. Effects of metal micro and nano-particles on hASCs: an in vitro model. Nanomaterials 7(212), 1-14 (2017).

11. Klimczak A, Kozlowska U. Mesenchymal stromal cells and tissue-specific progenitor cells: their role in tissue homeostasis. Stem Cells Int. 4285215 (2016).

12. Choi SY, Song MS, Ryu PD, Lam AT, Joo SW, Lee SY. Gold nanoparticles promote osteogenic differentiation in human adipose-derived mesenchymal stem cells through the Wnt/B-catenin signalling pathway. Int. J. Nanomedicine 10, 4383-4392 (2015).

13. Mancuso L, Cao G. Acute toxicity test of $\mathrm{CuO}$ nanoparticles using human mesenchymal stem cells. Toxicol. Mech. Methods 24(7), 449-454 (2014).

14. Hackenberg S, Scherzed A, Kessler M et al. Silver nanoparticles: evaluation of DNA damage, toxicity and functional impairment in human mesenchymal stem cells. Toxicol. Lett. 201(1), 27-33 (2011).

15. Sabbioni E, Fortaner S, Farina $\mathrm{M}$ et al. Interaction with culture medium components, cellular uptake and intracellular distribution of cobalt nanoparticles, microparticles and ions in Balb/3T3 mouse fibroblasts. Nanotoxicology 8(1), 88-99 (2014).

16. Cherubino M, Valdatta L, Balzaretti R et al. Human adipose-derived stem cells promote vascularization of collagen-based scaffolds transplanted into nude mice. Regen. Med. 11(3), 261-271 (2016).

17. Pirrone C, Gobbetti A, Caprara C, Bernardini G, Gornati R, Soldati G. Chondrogenic potential of hASCs expanded in flask or in a hollow-fiber bioreactor. J. Stem Cell Res. Med. 2(2), 1-10 (2017).

18. Strioga M, Viswanathan S, Darinskas A, Slaby O, Michalek J. Same or not the same? Comparison of adipose tissue-derived versus bone marrow-derived mesenchymal stem and stromal cells. Stem Cells Dev. 21, 2724-2752 (2012).

19. Palombella S, Pirrone C, Cherubino M, Valdatta L, Bernardini G, Gornati R. Identification of reference genes for qPCR analysis during hASC long culture maintenance. PLoS ONE 12(2), 1-12 (2017).

20. Rossi F, Bernardini G, Bonfanti P, Colombo A, Prati M, Gornati R. Effects of TCDD on spermatogenesis related factor-2 (SRF-2): gene expression in Xenopus. Toxicol. Lett. 191, 189-194 (2009).

21. Papis E, Gornati R, Ponti J, Prati M, Sabbioni E, Bernardini G. Gene expression in nanotoxicology: a search for biomarkers of exposure to cobalt particles and ions. Nanotoxicology 1(3), 198-203 (2007).

22. Ong KJ, MacCormack TJ, Clark RJ et al. Widespread nanoparticle-assay interference: implications for nanotoxicity testing. PLoS ONE 9(3), 1-9 (2014).

23. Almutary A, Sanderson BJ. The MTT and crystal violet assays: potential confounders in nanoparticle toxicity testing. Int. J. Toxicol. 35(4), 454-462 (2016).

24. Costa C, Brandão F, Bessa MJ et al. In vitro cytotoxicity of superparamagnetic iron oxide nanoparticles on neuronal and glial cells. Evaluation of nanoparticle interference with viability tests. J. Appl. Toxicol. 36(3), 361-372 (2016).

25. Pem B, González-Mancebo D, Moros M et al. Biocompatibility assessment of up- and down-converting nanoparticles: implications of interferences with in vitro assays. Methods Appl. Fluoresc. 7(1), 1-15 (2018).

26. Fröhlich E. Cellular elimination of nanoparticles. Environ. Toxicol. Pharmacol. 46, 90-94 (2016).

27. Kim C, Tonga GY, Yan B et al. Regulating exocytosis of nanoparticles via host-guest chemistry. Org. Biomol. Chem. 13(8), 2474-2479 (2015).

- Relevant to take note about the issue of the nanoparticle clearance.

28. Tsuji W, Rubin JP, Marra KG. Adipose-derived stem cells: implications in tissue regeneration. World J. Stem Cells 6(3), 312-321 (2014).

29. Bava A, Cappellini F, Pedretti E et al. Heparin and carboxymethylchitosan metal nanoparticles: an evaluation of their cytotoxicity. BioMed. Res. Int. 2013, 1-10 (2013).

-• Helps to approach topic related to nanoparticle internalization, toxicity and mechanical damage.

30. Eixenberger JE, Anders CB, Hermann RJ et al. Rapid dissolution of $\mathrm{ZnO}$ nanoparticles induced by biological buffers significantly impacts cytotoxicity. Chem. Res. Toxicol. 30(8), 1641-1651 (2017).

- To take note about the issue of the nanoparticle dissolution.

31. Littmann E, Autefage $\mathrm{H}$, Solanki AK et al. Cobalt-containing bioactive glasses reduce human mesenchymal stem cell chondrogenic differentiation despite HIF-1 $\alpha$ stabilisation. J. Eur. Ceram. Soc. 38, 877-886 (2018).

32. Cappellini F, Hedberg Y, McCarrick S et al. Mechanistic insight into reactivity and (geno)toxicity of well-characterized nanoparticles of cobalt metal and oxides. Nanotoxicology 12(6), 602-620 (2018).

33. Simonsen LO, Harbak H, Bennekou P. Cobalt metabolism and toxicology - a brief update. Sci. Total Environ. 432, 210-215 (2012).

34. Kroemer G, Marin G, Levine B. Autophagy and the integrated stress response. Mol. Cell 40, 280-293 (2010). 
35. Molejon MI, Ropolo A, Lo Re A, Boggio V, Vaccaro MI. The VMP1-Beclin 1 interaction regulates autophagy induction. Sci. Rep. 3, $1-11(2013)$

36. Calvo-Garrido J, Carilla-Latorre S, Escalante R. Vacuole membrane protein 1, autophagy and much more. Autophagy 4, 835-837 (2008).

37. Jie G, Wang Y, Liu Y et al. Inhibition of autophagy alleviates cadmium-induced mouse spleen and human B cells apoptosis. Toxicol. Sci. 170(1), 109-122 (2019).

38. Catelasa I, Petitb A, Valic $\mathrm{H}$ et al. Quantitative analysis of macrophage apoptosis vs. necrosis induced by cobalt and chromium ions in vitro. Biomaterials 26, 2441-2453 (2005).

- Helps in comprehending the apoptosis process.

39. Ortega R, Bresson C, Darolles C et al. Low-solubility particles and a Trojan-horse type mechanism of toxicity: the case of cobalt oxide on human lung cells. Part Fibre Toxicol. 11, 1-18 (2014).

-. Helps to understand the Trojan-horse mechanism correlated to low solubility.

40. Filvaroff E, Calautti E, Reissll M, Dotto GP. Functional evidence for an extracellular calcium receptor mechanism triggering tyrosine kinase activation associated with mouse keratinocyte differentiation. J. Biol. Chem. 269(34), 21735-21740 (1994).

41. Oh N, Park JH. Endocytosis and exocytosis of nanoparticles in mammalian cells. Int. J. Nanomed. 9(1), 51-63 (2014).

-. Helps to understand endocytosis and exocytosis patterns of nanoparticles.

42. Pham BTT, Colvin EK, Pham NTH et al. Biodistribution and clearance of stable superparamagnetic maghemite iron oxide nanoparticles in mice following intraperitoneal administration. Int. J. Mol. Sci. 19(1), 1-23 (2018). 